\title{
CARACTERIZAÇÃO CLIMÁTICA REGIONAL DO RIO GRANDE DO SUL: DOS ESTUDOS ESTÁTICOS AO ENTENDIMENTO DA GÊNESE
}

\author{
WOLLMANN, Cássio Arthur - cassio_geo@yahoo.com.br \\ CCNE / UFSM-RS - Universidade Federal de Santa Maria \\ GALVANI, Emerson - egalvani@usp.br \\ Dep Geografia / FFLCH-USP - Faculdade de Filosofia, Letras e Ciências Humanas da \\ Universidade de São Paulo
}

\begin{abstract}
Resumo
Ao se trabalhar com o clima do Rio Grande do Sul com a finalidade de entender sua dinâmica socioeconômica e ambiental constata-se com uma infinidade de pesquisas científicas abordando a temática proposta. Assim, com o intuito de resgatar os principais autores e trabalhos realizados por estes durante o século XX é que se propôs esta pesquisa. Nesta seara, cabe salientar a existência de duas grandes Linhas teórico-metodológicas no que concernem os estudos em Climatologia no Estado: a primeira diz respeito ao estudo estático do clima, salientando as médias e totais registrados a partir da análise dos atributos climáticos baseando-se na definição clássica de clima de Hann (1882); aos sistemas atmosféricos que compõem o quadro climático sul-rio-grandense e as consequentes sucessões de tipos de tempo, aplicando-se o conceito de clima de Sorre (1957).

Palavras-chave: Evolução histórica dos estudos; Climatologia Regional; Rio Grande do Sul;
\end{abstract}

THE THEORETICAL LINES OF RESEARCH AND THE STUDIES OF GEOGRAPHICAL CLIMATOLOGY IN RIO GRANDE DO SUL IN THE TWENTIETH CENTURY

\section{Abastract}

When working with the climate of Rio Grande do Sul in order to understand its dynamics socioeconomic and environmental notes with a plethora of scientific research addressing this topic. Thus, in order to rescue the major authors and works carried out by them during the twentieth century is that this proposed research. In this field, it should be noted that there are two major lines theoretical and methodological studies that concern the State Climatology: the first concerns the static study climate, highlighting the averages and totals recorded from the analysis of climatic attributes based the classic definition of climate Hann (1882), the atmospheric systems that comprise the climate south of Rio Grande and the resulting succession of weather types, applying the concept of climate Sorre (1957).

Keywords: Historical evolution studies; Regional Climatology; Rio Grande do Sul

\section{INTRODUÇÃO}

Os estudos científicos que abordam o clima, em qualquer âmbito, seja ele geográfico, físico-matemático ou meteorológico tem aumentado a quantidade de trabalhos realizados e observados nos últimos congressos brasileiros da área.

Ao se trabalhar com a caracterização climática de determinado recorte espacial, além de ser necessário o resgate teórico, há pelo menos, duas formas de levantamento e tratamento de dados climáticos: uma conhecida como caracterização, ou classificação, estática, e outra dinâmica.

A primeira consiste, em analisar os elementos climáticos e a sua distribuição na superfície terrestre recorrendo-se a métodos estatísticos elaborados. Já a segunda consiste em analisar a dinâmica atmosférica recíproca à área de estudo, trabalhando com noções de sistemas atmosféricos (massas de ar e correntes perturbadas) e sua dinamicidade (ritmo), imprescindivelmente, em escala temporal diária e com dados levantados em trabalho de campo.

No entanto, construir a caracterização do clima de determinado recorte espacial requer minuciosa busca por parte do pesquisador, pois geralmente as principais

$$
\text { Ano } 8 \text { - Vol. } 11 \text { - JUL/DEZ } 2012
$$


obras, especialmente as mais antigas, não se encontram sistematizadas em um único local ou base de artigos e teses.

Nesse sentido, surge a necessidade de sistematização desse conhecimento para o Rio grande do Sul. Dessa forma, o objetivo geral desta pesquisa consistiu em propor uma caracterização regional, estática e dinâmica, do clima com a finalidade de sistematizar as principais pesquisas e referenciais teóricos deste tema para o Estado, desenvolvidas entre 1930 a 2000, procurando-se, também, facilitar a busca por trabalhos desta natureza a quem possa interessar.

O critério de seleção dos autores discutidos nesta pesquisa foi baseado na existência das principais obras utilizadas em pesquisas de caracterização climática apenas para o Rio Grande do Sul. Nesse sentido, foram descartadas obras que tratassem do clima da Região Sul, Brasil e/ou América do Sul, mesmo que contemplassem o Estado e, suas referências. Ainda, não foram utilizadas obras de caracterização e aplicação local do clima, que são comuns em anais de congressos.

\section{OS ESTUDOS CLIMÁTICOS NO RIO GRANDE DO SUL NO SÉCULO XX: RESGATE HISTÓRICO E ESTADO DA ARTE ATUAL}

Em termos de classificação climática geral, o Estado do Rio Grande do Sul insere-se no tipo Cfa e Cfb, proposto por Köppen (1931), sendo:

C - clima temperado chuvoso e quente

$\boldsymbol{f}$ - nenhuma estação seca

a - verão quente e mês mais quente com temperatura média maior do que $22^{\circ} \mathrm{C}$ e a do mês mais frio superior a $3^{\circ} \mathrm{C}$.

$\boldsymbol{b}$ - Temperatura média do ar no mês mais quente é menor que $22^{\circ} \mathrm{C}$ e a temperatura média do ar nos 4 meses mais quentes é superior a $10^{\circ} \mathrm{C}$.

Entretanto, ao se trabalhar com o clima do Rio Grande do Sul com a finalidade de entender sua dinâmica e sua influência no espaço geográfico, depara-se com uma infinidade de pesquisas científicas que o abordam.

No âmago destas pesquisas distinguem-se pelo menos duas grandes linhas teórico-metodológicas no que cocernem os estudos climáticos para este recorte espacial: a primeira diz respeito ao estudo estático do clima, salientando as médias e totais registrados a partir da análise dos elementos climáticos. Já a segunda remete à dinâmica atmosférica em escala regional e local, ou seja, salientando os sistemas atmosféricos que compõem o quadro climático sul-riograndense e as consequentes sucessões de tipos de tempo.

$\mathrm{Na}$ primeira perspectiva, buscou-se uma análise sobre a pluviometria, temperatura e ventos (estes, juntamente com a pluviometria, podem ser considerados indicadores prévios da dinâmica climática de dado recorte espacial - Wollmann, (2011)), tanto nos seus totais, quanto inserir médias mensais e 
anuais. Na segunda perspectiva, buscou-se a gênese e dinâmica atmosférica para o Estado.

\section{1 - CLIMATOLOGIA ESTÁTICA}

\section{a) Precipitação Pluviométrica}

Cabe salientar que a caracterização climática de determinada área pode ser inicialmente feita através da análise da precipitação pluviométrica, pois pode refletir as condições de circulação atmosférica regional, tanto sazonal quanto anual.

Nesta primeira vertente científica, destaca-se o trabalho pioneiro de Araújo (1930, p. 48 - 49), que, ao abordar as regiões mais chuvosas do Rio Grande do Sul, enfatiza que:

Na distribuição Geográfica das chuvas tem, entretanto, a orografia do Rio Grande do Sul sensível influencia, pois os obstáculos que a caracterizam aumentam, por si mesmo, o movimento ascensional do ar, que é a causa mais eficaz da produção de chuva. Assim, a região em que mais chove no estado é a parte mais alta da Serra do Nordeste, ultrapassando, ali, a altura da chuva anual $2000 \mathrm{~mm}$.

O referido autor apresenta uma breve classificação para as chuvas do Rio Grande do Sul, chamando-as de normais, escassas ou abundantes ${ }^{1}$. Ainda citando, as chuvas no Rio Grande do Sul não possuem uma época específica em que os totais são maiores ou menores, mas destaca um pequeno aumento entre as diferentes estações do ano, afirmando que:

Há dois tipos de chuva, o primeiro é o do oeste, inicia-se em março e termina em junho, e pode ser chamado tipo de chuvas de Outono; e o segundo, é o da parte leste, inicia-se em junho e finaliza em setembro, acentuando-se em agosto e setembro na parte nordeste do estado, e pode ser determinado tipo de chuvas de inverno [Trecho com correção ortográfica e gramatical].

Além de Araújo (op. cit.), Machado (1950) também estuda o clima do Rio Grande do Sul sob a perspectiva empírica, e chega a resultados muito semelhantes aos do primeiro autor. Dos totais anuais registrados no Estado, $27 \%$ das chuvas correspondem ao regime de primavera, de $28 \%$ a $31 \%$ aos de outono, $28 \%$ aos de inverno e o restante ao regime de verão (Machado, op. cit., p. 24).

\footnotetext{
${ }^{1}$ Aqui, pode-se fazer uma analogia com os anos-padrão habituais, menos chuvosos e mais chuvosos, respectivamente.
} 
Dessa forma, para Machado (op. cit.) não há uma estação definida para as chuvas no Estado, precipitando praticamente os mesmos valores ao longo do ano. No entanto, o autor faz rápida menção aos totais pluviométricos mais elevados na Serra do Nordeste, onde se constata a influência do relevo.

Ainda nessa linha de pesquisa destaca-se o trabalho de Moreno (1961, p. 19), que também explana a regularidade anual das chuvas no Rio Grande do Sul, não havendo, portanto, chuvas periódicas ou sazonais, especialmente por quê:

"Um clima para se classificar como de chuvas de inverno, precisa apresentar: chuva periódica, e no mês mais chuvoso, de inverno, as precipitações devem ser três vezes, ou mais, de maior altura que no mês mais seco".

Para chegar a essa conclusão, o autor baseou-se na classificação climática de Köppen (op. cit.), em que o Rio Grande do Sul, pode ser classificado como Cfa e $\mathrm{Cfb}$, que significam úmidos em todas as estações, com verão quente e moderadamente quente, respectivamente.

Com Moreno (op. cit., p. 21), é que começa a ser abordada a caracterização dinâmica do clima do Rio Grande do Sul no que concerne a gênese das precipitações aliado aos fatores estáticos e geográficos, como a influência do relevo sobre os totais pluviométricos do Estado. Para o autor:

O regime pluviométrico do Estado além de sua formação pelos deslocamentos dos anticiclones de inverno e as da frente tropical, é acentuado pela orografia. Onde esta aparece, as chuvas se precipitam em maiores volumes. 0 relevo obriga a elevação das massas, as quais se resfriam, condensam-se, ocasionando as chuvas.

Vê-se, portanto, que o autor faz rápida sugestão quanto à circulação atmosférica responsável pelas chuvas no Rio Grande do Sul. Entretanto, a terminologia não foi empregada corretamente quanto à zona de origem, quando o autor se refere ao termo "frente tropical", pois sua gênese está ligada á zona frontogenética do globo, em latitudes subpolares $\left(50^{\circ}\right.$ a $\left.70^{\circ}\right)$, tanto no Hemisfério Sul quanto no Norte.

Para melhor ilustrar as colocações dos autores anteriormente analisados, a Figura 01 mostra a distribuição espacial da pluviometria e da temperatura no território sul-rio-grandense anualmente, bem como a altimetria, a fim de visualizar melhor a distribuição temporo-espacial da precipitação e a influência do relevo como controle deste atributo climático no Rio Grande do Sul. 


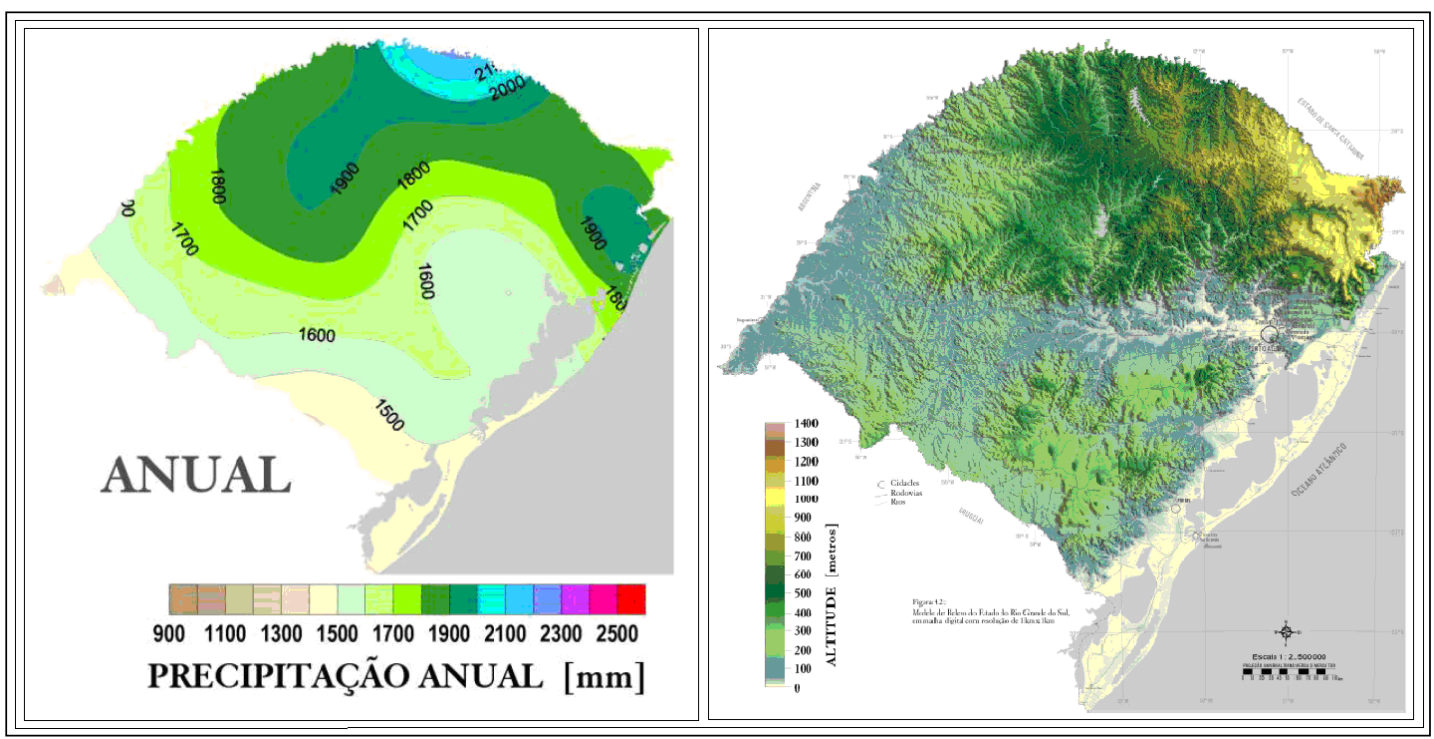

Figura 01 - Distribuição espacial anual da precipitação e altimetria no Estado do Rio Grande do Sul.

Fonte: Atlas Socioeconômico do Rio Grande do Sul / SEMA, 2006.

Adapt. e Org.: Org.: WOLLMANN, C. A., 2013.

\section{b) Temperatura do Ar}

No que se refere às temperaturas, Araújo (op. cit.) enfatiza em suas pesquisas as amplitudes térmicas anuais, principalmente comparando as médias de janeiro e julho (meses representativos de verão e inverno, respectivamente) e ainda, classificando o Estado em oito regiões térmicas. Para o autor:

No Rio Grande do Sul, as variações de altitude, a continentalidade e a vizinhança de grandes massas d'água, são os fatores físicos que produzem modificações mais sensíveis na temperatura. Assim, as isotermas do Estado, em vez de ocorrerem ao longo dos paralelos, formam, por efeito das altitudes, dois centros de valores mínimos ao redor dos pontos mais elevados das Serras do Nordeste e do Sueste; e, seguindo as linhas de igual altura, vão aumentando de valor, até atingir o seu máximo, por efeito de continentalidade, no Baixo Valle do Uruguai e no Oeste da Depressão Central, e não alcançam senão um valor médio anual relativamente baixo, por influência da vizinhança de grandes massas d'água no Litoral [Trecho com correção ortográfica e gramatical].

Para melhor caracterizar a temperatura no Rio Grande do Sul e a classificação do Estado em oito regiões criadas por Araújo (op. cit.), a Tabela 01 
mostra de forma sucinta os valores médios de temperatura para janeiro e julho, bem como a amplitude registrada.

Tabela 01 - Valores médios de temperatura $\left({ }^{\circ} \mathrm{C}\right)$ para janeiro e julho, e amplitude anual registrada nas oito regiões térmicas do Rio Grande do Sul.

\begin{tabular}{lrrr}
\hline \multicolumn{1}{c}{ Regiões } & Janeiro & Julho & Amplitude Anual \\
\hline Campanha & 24,4 & 12,1 & 12,3 \\
Serra do Sudeste & 21,6 & 11,3 & 10,3 \\
Litoral & 22,5 & 12,0 & 10,5 \\
Depressão Central & 24,6 & 13,3 & 11,3 \\
Vale do Uruguai & 25,9 & 13,8 & 12,1 \\
Missões & 23,2 & 14,1 & 10,1 \\
Planalto & 21,9 & 12,1 & 9,5 \\
Serra do Nordeste & 20,6 & 11,1 & 9,5 \\
Campanha & 24,4 & 12,1 & 12,3 \\
Serra do Sudeste & 21,6 & 11,3 & 10,3 \\
Litoral & 22,5 & 12,0 & 10,5 \\
Média Estadual & 23,2 & 12,4 & 10,8 \\
\hline
\end{tabular}

Fonte: ARAÚJO, L. C. (1930).

ORG.: WOLLMANN, C. A., 2013.

Em relação às temperaturas, as conclusões de Machado (op. cit.) assemelhamse muito às de Araújo (op. cit.), aproximando-se da classificação do primeiro autor quanto à regionalização da temperatura no Rio Grande do Sul em oito regiões. Em análise sazonal, a respeito do verão, Machado (1950) coloca que a estação possui médias semelhantes a do mês de janeiro, considerado pelo autor, como o mês mais quente da estação e, consequentemente, do ano. Ainda para o verão, o autor aborda que os meses mais e menos quente são, respectivamente, fevereiro e dezembro.

Entretanto, Machado (op. cit.) vai além, ressaltando a ocorrência de ondas de frio e ondas de calor no Estado. Para o autor, onda de frio pode ser conceituada como um fenômeno meteorológico que possui como principal característica uma forte queda de temperatura, em geral podendo alcançar valores negativos, dentro de certo período, em média de 3 a 9 dias, podendo ocorrer em geral de maio a setembro, especialmente no Planalto e Serra do Sudeste, que são as áreas com maiores altitudes do Estado. No que diz respeito às ondas de calor, elas podem ocorrer de dezembro à março, e são caracterizadas quando as temperaturas máximas ultrapassarem os $33^{\circ} \mathrm{C}$ e as temperaturas mínimas ficarem acima de $19^{\circ} \mathrm{C}$, por 3 ou 4 dias (Machado, op. cit., p. 17).

Em estudos posteriores, Moreno (1961, p. 16), afirmou que "... a variação da temperatura no Rio Grande do Sul está na dependência da movimentação das massas de ar, das diferentes altitudes, da maritimidade e da continentalidade". Como o autor baseou-se na classificação climática de Köppen, no que concerne a 
temperatura, Moreno (op. cit.) também conclui a existência de climas tipo Cfa e Cfb no Rio grande do Sul.

Novamente Moreno (1961) reafirma o que pioneiramente já tinha mencionado Araújo (1930, p. 27), quando escreve "Em geral, os dias de mais alta temperatura do ano ocorrem entre 15 de dezembro e fins de janeiro. Há, entretanto, casos em que se tem verificado temperaturas máximas absolutas em novembro..., em fevereiro... e mesmo em março...".

\section{c) Ventos}

Ao se trabalhar com a caracterização climática de determinado recorte espacial, um dos principais elementos climáticos a serem analisados são os ventos, justamente por serem fortemente associados a prejuízos socioeconômicos e materiais do espaço geográfico.

O regime anual de ventos na área de estudo apresenta variação ligada aos anticiclones (Anticiclone Subtropical Atlântico e Anticiclone Migratório Polar) e suas respectivas massas de ar em sua constante dinâmica. Conforme relata a SEMC (2002, p. 12), "No escoamento atmosférico sobre o Rio Grande do Sul prevalecem efeitos ditados pela dinâmica entre o anticiclone subtropical Atlântico, os intermitentes deslocamentos de massas polares e a depressão barométrica do nordeste da Argentina".

Sobre o estudo da direção e velocidade dos ventos no Rio Grande do Sul, a Figura 02 mostra de forma geral a dinâmica sazonal e diária dos ventos no Estado.

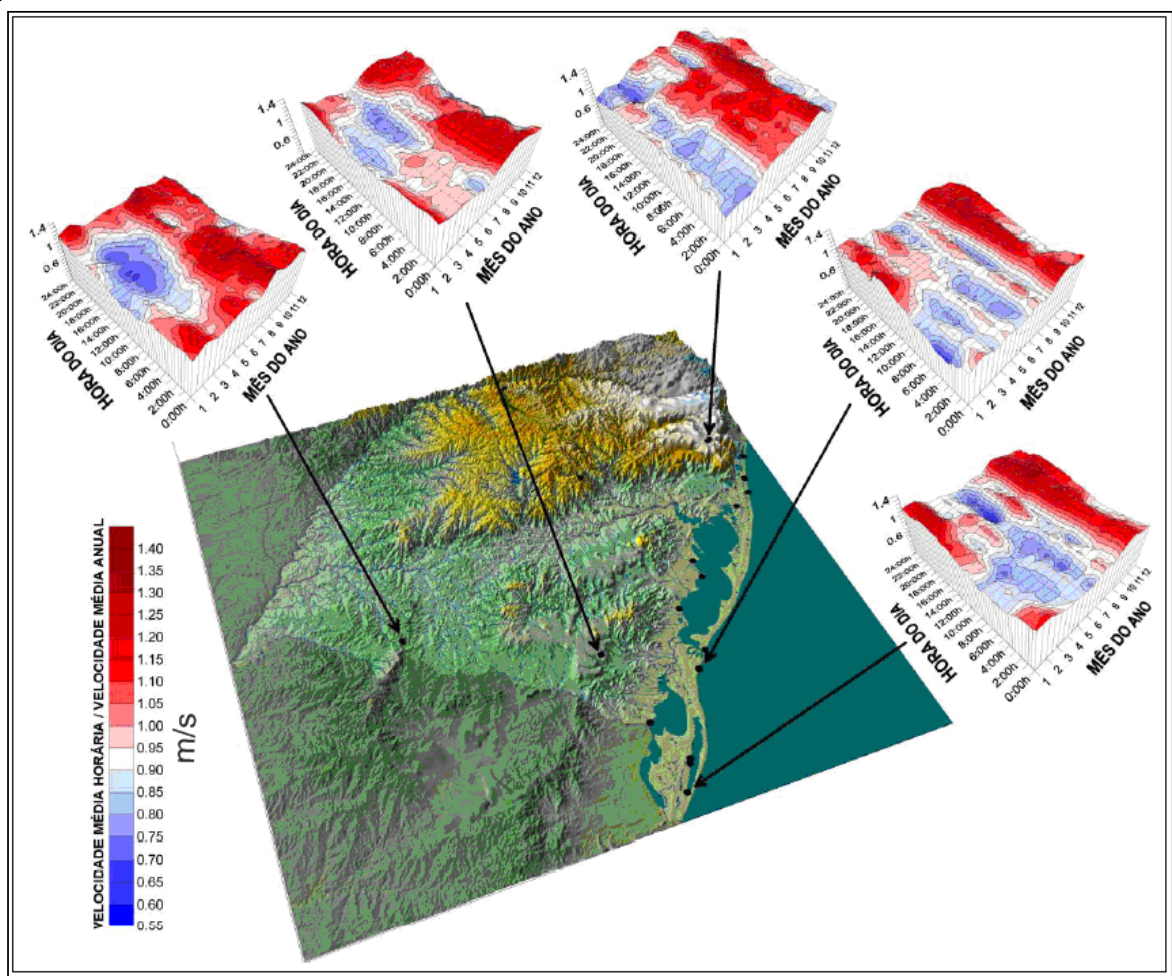

Figura 02 - Regimes diurnos e mensais de ventos nas diversas regiões do Rio Grande do Sul.

Fonte: Atlas Eólico do Rio Grande do Sul (SEMC, 2002). ORG.: WOLLMANN, C. A., 2013. 
De acordo com a Figura 02, na Campanha e Serras do centro e oeste do Estado, as velocidades do vento se intensificam durante o período noturno, amenizandose durante a manhã, especialmente no verão e no outono. Nas serras do Planalto da Bacia do Paraná os ventos tendem a ser mais fracos durante os meses de verão e no início da noite. Ao longo do litoral, por fim, observa-se a atuação da brisa marinha durante o período diurno, especialmente na primavera e verão.

\section{2 - CLIMATOLOGIA GENÉTICA, OU DINÂMICA}

a) Centros de Ação e Participação de Sistemas Atmosféricos

Sobre os Centros de Ação que dominam sobre o Território Sul-Rio-grandense, o Anticiclone Migratório Polar (AMP), que se origina por acúmulo de ar frio em latitudes subpolares $\left(60^{\circ} \mathrm{S}\right)$ sobre o Oceano Pacífico, possui ar frio e estável, e migra constantemente para o continente, tornando-se o "... principal responsável pela formação dos tipos de tempo da Região Sul, em virtude da atuação de Massas Polares e da ação das Frentes Frias" (MONTEIRO, 1963, p. 122).

Além do AMP, outros centros de ação dominam sobre o Estado, principalmente a Baixa do Chaco e o Anticiclone Tropical Atlântico, que podem ser visualizados através da Figura 03.

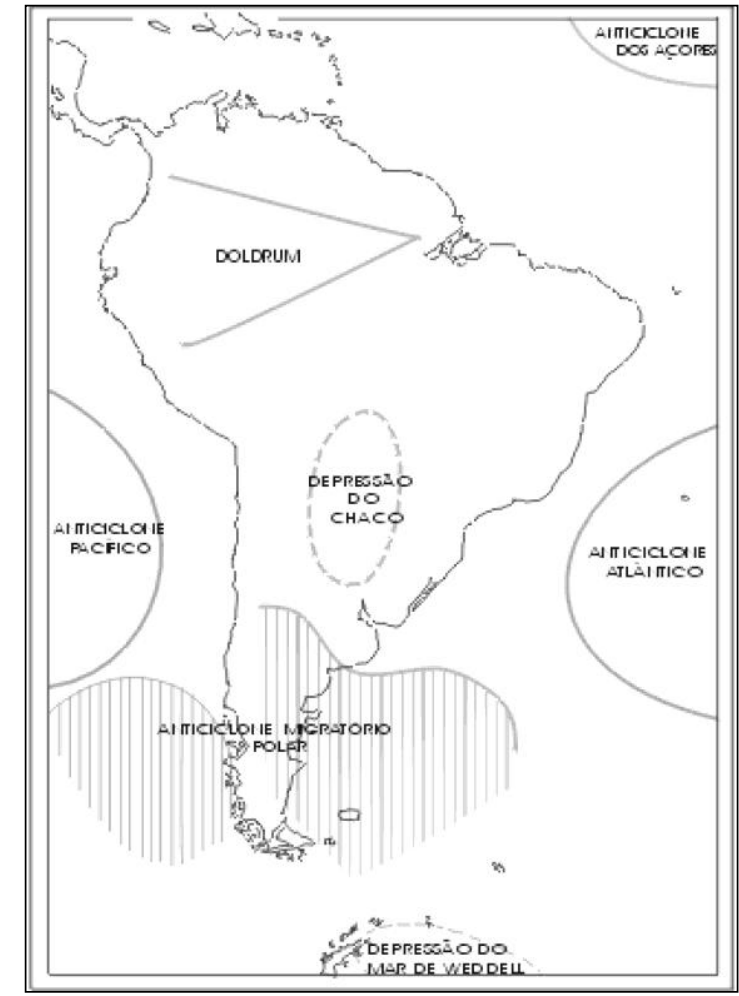

Figura 03 - Centros de Ação da América do Sul.

Fonte: MONTEIRO (1963). ADAPT.: WOLLMANN, C. A., 2013. 
Em Sartori (2003), que investigou de maneira mais profunda a dinâmica dos Centros de Ação no Estado, a autora afirma que a participação dos sistemas atmosféricos extratropicais na sucessão do tempo (circulação secundária regional) são mais presentes, mesmo durante o verão.

No verão (22 de dezembro a 20 de março), compreendendo 89 dias, a participação maior é da MPV que, em média, domina em mais de $45 \%$ dos dias da estação. A FPA aparece em segundo lugar no número de dias sob seu domínio... totalizando mais de $20 \%$ dos dias de verão, embora em sua passagem nem sempre se registrem precipitações. A MPA típica tem participação em cerca de $19 \%$ dos dias... Entre os Sistemas Intertropicais, a MTA, incluindo sua interiorização (MTAc), e a MTC são as que têm maior participação na circulação atmosférica regional, dominando em cerca de $5 \%$ dos dias cada uma... Além das massas de ar de origem tropical, há atuação das Instabilidades Tropicais ou de Noroeste e de Calhas Induzidas em cerca de $7 \%$ e $5 \%$ dos dias, respectivamente, associadas às fases préfrontais e independentes da massa de ar dominante [...] (SARTORI, 2003, p. 29-30).

b) Centros de Ação, Circulação Atmosférica Regional e Participação de Sistemas Atmosféricos e a Gênese dos Principais Atributos do Clima.

Adentrando na caracterização climática sob o ponto de vista dinâmico da atmosfera, o primeiro autor a abordar essa linha teórico-metodológica para a Região Sul é Monteiro (1963, p. 152), quando escreve:

Assim, dentro deste ponto de vista, pode-se fazer a seguinte distinção. Em cerca das três das quartas partes mais meridionais da região, as chuvas se distribuem pelo correr do ano de modo a não haver período seco... É a característica pluvial da região. Em quase todas as localidades selecionadas não há mês de pluviosidade inferior à $60 \mathrm{~mm}$, há não ser em alguns poucos casos excepcionais. Dentro da circulação atmosférica regional, este resultado é logicamente compreendido: atuação de massas úmidas, mecanismos frontais, efeito orográfico, etc.

Neste sentido, o autor também enfoca o efeito do relevo da Região Sul como um dos intensificadores da pluviometria, ao afirmar que: 
Como se sabe, a pluviosidade, em que pesem as correntes gerais da atmosfera, desencadeadoras dos tipos de tempo, estão sujeitas a importantes variações segundo os fatores locais. Considerando esse fato percebe-se... as influencias que as linhas gerais do relevo oferecem as correntes de descontinuidades fomentadoras da pluviosidade. Mas o que é de maior interesse geográfico é a distribuição das chuvas no decorrer do ano (MONTEIRO, 1963, p. 152).

Entretanto, na análise sazonal da pluviometria, para Monteiro (op. cit., p. 154) ocorre um aumento dos totais de chuva no outono, fruto das "frentes indecisas", cujo "... eixo principal da FPA oscila mais frequentemente entre o Rio da Prata e o Rio Grande [do Sul], deixando ali, boa parte de suas precipitações". Ainda, o autor constatou e diferenciou o deslocamento e a passagens da Frente Polar Atlântica durante o inverno e o verão, o que pode ser melhor visualizado através da Figura 04.

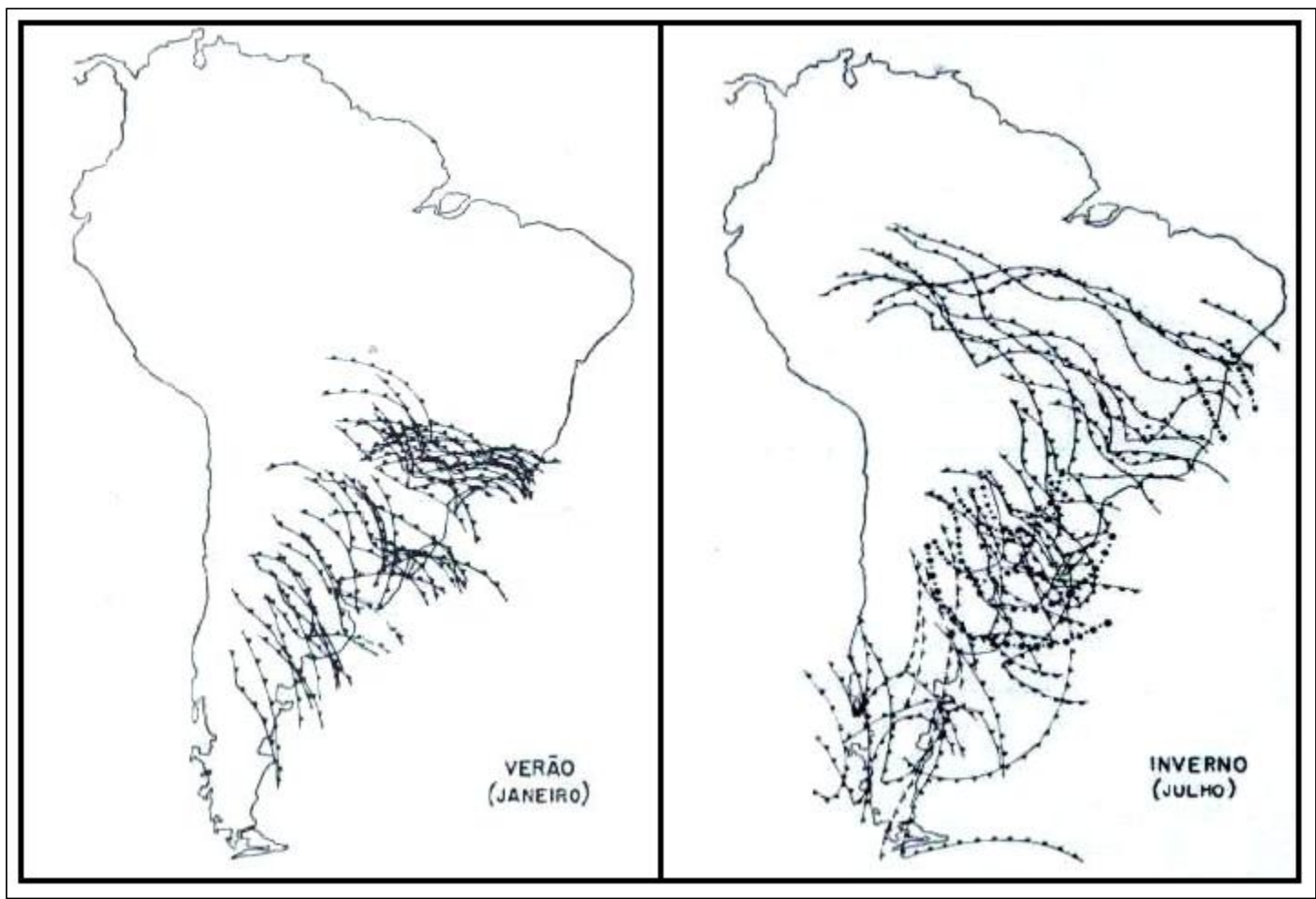

Figura 04 - Posição da Frente Polar durante o inverno e o verão na América do Sul. Fonte: MONTEIRO, 1963. Adapt. e Org.: Org.: WOLLMANN, C. A., 2013.

Neste resultado, portanto, pode-se inferir que as chuvas no outono podem ocorrer na passagem desta estação com o inverno, e principalmente neste, quando há uma intensificação dos sistemas polares e tropicais, intensificando os 
processos frontogenéticos e as precipitações frontais (Monteiro, op. cit.; Sartori, 1993a, 2003a).

Para Monteiro (1963), durante o outono as Frentes Polares (FPA), começam a tornar-se mais fortes devido ao resfriamento do Hemisfério Sul, intensificando a formação das massas de ar do referido hemisfério, e que tem participação no Brasil, em especial no Rio Grande do Sul, como a Massa Polar Atlântica (MPA) e a Massa Tropical Atlântica (MTA), gerando Frentes Quentes (FQ) e intensas ciclogêneses.

Para a primavera, Sartori (2003; p. 71) avalia que "... os fluxos de origem intertropical tendem a aumentar seu valor de frequência na região pelo enfraquecimento da intensidade dos fluxos polares, motivado pela redução dos gradientes térmicos latitudinais e pelo aquecimento do Hemisfério".

Em relação ao inverno do Rio Grande do Sul, em função de uma menor incidência da radiação solar, SARTORI (op. cit., p. 30-31) coloca que:

A participação de FPA é maior no inverno, permanecendo sobre o estado em mais de $22 \%$ dos dias, com aumento dos casos de frentes estacionárias e de ciclogêneses (formação de ciclones frontais), situações atmosféricas responsáveis pelos grandes índices pluviométricos que podem ocorrer no inverno... As Correntes Perturbadas, como Instabilidades Tropicais e Calhas Induzidas, controlam cerca de $3 \%$ dos dias e são responsáveis pelas chuvas e/ou granizo que antecedem a FPA, muitas vezes confundindo-as, sem que se saiba quais as chuvas relacionadas às perturbações pré-frontais e quais as provenientes da passagem de Frente Fria.

De uma maneira geral, a Figura 05 apresenta a participação dos sistemas de correntes perturbadas atuantes no Sul do Brasil, na qual se observa o predomínio das Correntes Perturbadas de Sul (Frentes Polares) na gênese das chuvas. 


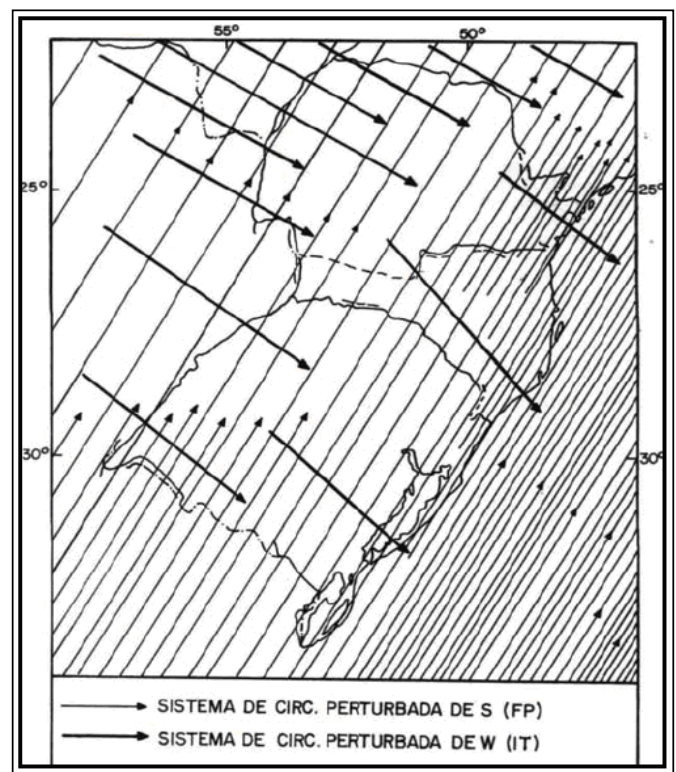

Figura 05 - Sistema de Circulação Atmosférica Perturbada atuante na Região Sul do Brasil.

FP - Frente Polar / IT - Instabilidade Tropical

Fonte: NIMER, 1979.

Adapt. e Org.: WOLLMANN, C. A., 2013.

As chuvas frontais, segundo Sartori (2003), representam cerca de 90 a $92 \%$ das correntes perturbadas que causam precipitação sobre o território sul-riograndense, ficando apenas $8-10 \%$ da precipitação sob influência de passagens de instabilidades tropicais.

Por fim, SARTORI (1993, p.178) classificou o Estado do Rio Grande do Sul em oito (8) regiões climáticas de acordo com as chuvas (Figura 08). SARTORI (op. cit.) ainda aborda que a umidade relativa do ar no referido Estado fica em torno de $70 \%$ a $85 \%$, sendo, evidentemente, maior no inverno, bem como o aumento da participação de nevoeiros no Estado entre os meses de maio a outubro (Machado, 1950).

Na Figura 06 é possível visualizar a correspondência entre as regiões climáticas definidas por Sartori e o mapa da distribuição espacial da precipitação no Rio Grande do Sul, elaborado pela Companhia de Pesquisa dos Recursos Minerais (CPRM, 2010). 


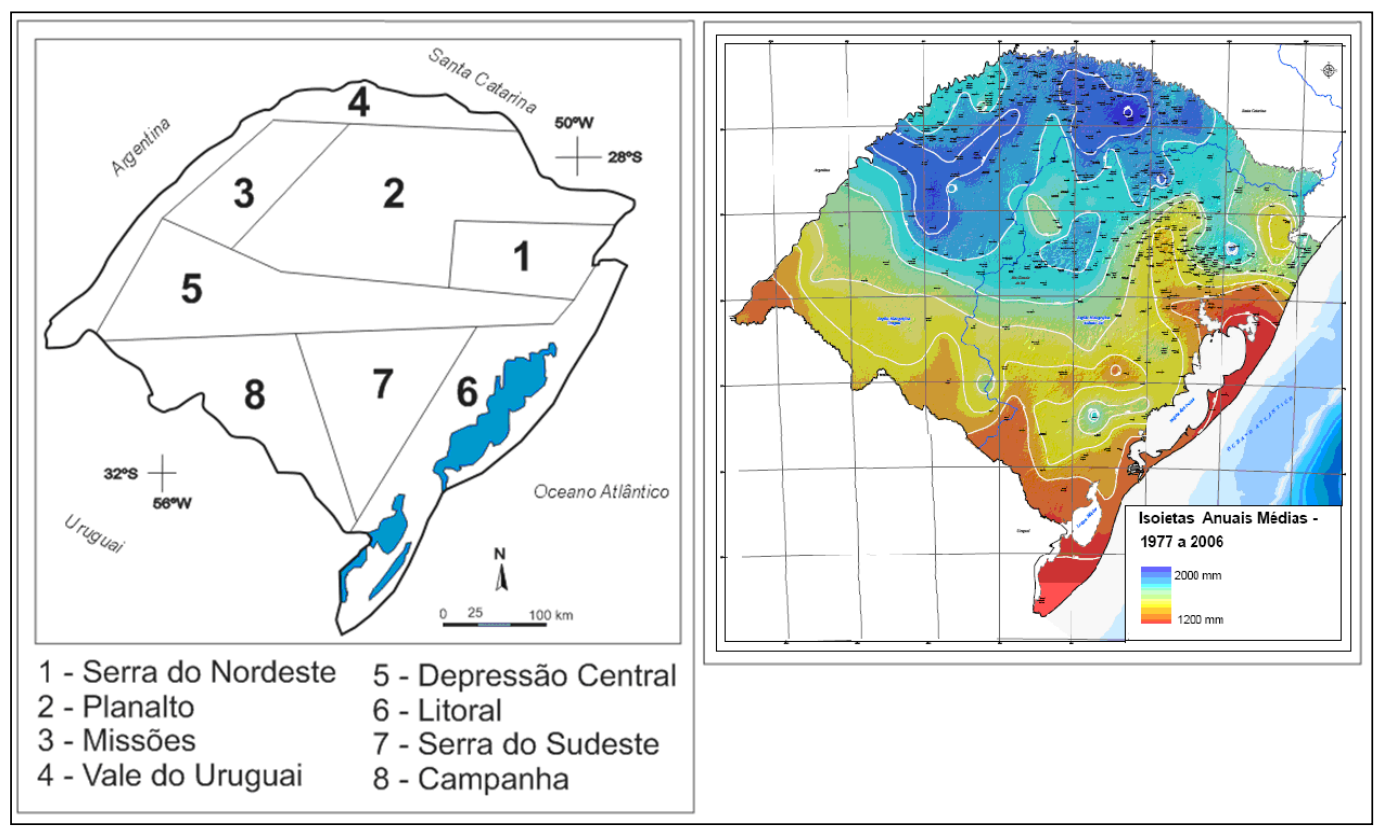

Figura 06 - Regiões Climáticas e Pluviometria Anual Total do Rio Grande do Sul. Fonte: SARTORI, M. G. B. (1993, p. 178); CPRM (2010).

ORG.: WOLLMANN, C. A., 2013.

No entanto, no que concerne a dinâmica atmosférica em relação ao deslocamento da Frente Polar Atlântica (FPA), a autora ressalta que esse tipo de sistema atmosférico apresenta ciclogêneses e oclusões muito mais frequentes no inverno.

Desse modo, pode-se estabelecer que os totais pluviométricos podem elevar-se um pouco acima do normal, especialmente no inverno, em função de modificações ocorridas no eixo principal da FPA, fruto de uma circulação peculiar da atmosfera durante o inverno sul-rio-grandense.

\section{$\underline{I}$ - Da Gênese dos Tipos de Tempo}

Diversos tipos de passagens frontais originam tipos de tempo que Sartori (2003) associou às Correntes Perturbadas de Sul (Frentes Polares). Nesse sentido, podem ser 6 (seis) os tipos de tempo frontais relacionados a gênese da pluviometria no Rio Grande do Sul:

Tempo Frontal de Sudoeste de Fraca Atuação - É resultado da formação de uma fraca frontogênese sobre o Rio Grande do Sul. Ainda, define-se pela passagem rápida da frente (menos de $1 \mathrm{dia}$ ).

Tempo Frontal de Sudoeste de Atuação Moderada - Provocado pela passagem habitual da Frente Polar Atlântica (FPA), sem permanecer sobre o território Sul-Rio-grandense, originando densa nebulosidade e chuvas de volume razoável, algumas vezes superiores a $50 \mathrm{~mm}$, com relâmpagos, raios e trovoadas: 
Tempo Frontal Estacionário - Quando, por pelo menos três dias, o eixo frontal permanece sobre o Estado, provocada pelo fraco fluxo polar ou bloqueio da circulação atmosférica regional pela influência do Anticiclone Tropical do Atlântico, que pode ocorrer, por exemplo, quando há a atuação do fenômeno El Niño, originando um tempo muito úmido, com chuvas de intensidade variada, e pequena amplitude térmica diária.

Tempo Frontal de Nordeste - Está relacionado à participação de uma Frente Quente, que é resultado do recuo da Frente Fria para o Rio Grande do Sul depois de já estar em latitudes mais baixas, como os Estados de Santa Catarina e Paraná. Podem ocorrer chuvas fortes.

Tempo Frontal Ciclonal de Atuação Direta - Atua sobre o Rio Grande do Sul a FPA, com formação definida de ciclone frontal, localizado sobre o Estado, resultando em céu totalmente encoberto, com chuvas fortes, muitas vezes superiores a $50 \mathrm{~mm}$.

Tempo Frontal Ciclonal de Atuação Indireta - Ocorre em situações quando o ciclone frontal está posicionado no Oceano Atlântico, na latitude do Rio Grande do Sul e Uruguai, com apenas o ramo continental da Frente, ou o vórtice, afetando o Estado.

Na análise da dinâmica atmosférica, Sartori (1993) definiu a sucessão do tempo através de fases evolutivas, sendo sensivelmente observada a participação da Frente Polar (FPA) nos seus diversos tipos de sucessão e domínio. Neste caso, deu-se a sucessão de tempo em 4 fases:

Fase Pré-frontal - Essa fase, com duração de 1 a 3 dias, pode ser caracterizada pelo aquecimento registrado antes da chegada da frente fria, com tipo de tempo muito bem definido: pressão atmosférica em declínio, e ventos do quadrante norte ( $\mathrm{N}$ ou NW).

Fase Frontal - Fase na qual ocorre a passagem da FPA sobre o Rio Grande do Sul, impondo-Ihe um tipo de tempo característico. Os ventos são variáveis (direção e velocidade), a pressão atmosférica registrada é a mínima dentre as fases que se registram, o céu apresenta-se encoberto e precipitações de maior ou menor intensidade, que podem às vezes não ocorrer.

Domínio Polar - Nesta fase as condições de tempo são impostas pelo domínio da Massa Polar Atlântica (MPA) no Rio Grande do Sul, resultando em grande declínio das temperaturas máximas e mínimas, podendo favorecer, dependendo da força desse sistema extratropical e da estação do ano, a ocorrência de geadas, orvalho, nevoeiro e até mesmo neve nas regiões mais elevadas do Planalto da Bacia do Paraná (Nordeste do Estado).

Fase Transicional - É uma fase de "transição" entre o domínio da MPA e nova fase Pré-Frontal. Caracteriza-se pelo domínio da Massa Polar modificada pelo aquecimento basal sobre latitudes mais baixas (Massas Polar Velha (MPV) ou Tropicalizada) em função do tempo de permanência do ar frio no Sul do Brasil. Em função da superfície continental e da forte insolação facilitada pelo 
céu limpo, a MPA é modificada no interior do continente, aquecendo-se basalmente, resultando em uma massa de ar de origem polar mais quente e seca.

Ainda, SARTORI (1993b, p. 83), baseando-se nos estudos estáticos de Araújo (1930), Machado (1950), Moreno (1961) e principalmente nos de Monteiro (1963), também conclui que:

A análise da distribuição sazonal, que define o regime das chuvas, comprovou que nenhuma das estações pode ser de fato considerada mais ou menos chuvosa... Entretanto, o outono tende a apresentar um maior número de índices percentuais acima dos $25 \%$, o que sugere é que a estação do ano com propensão a ser mais chuvosa na região central do Rio Grande do Sul.

Além da análise de tipos de tempo associados às correntes perturbadas, a autora apresenta tipos de tempo relacionados ao domínio de sistemas atmosféricos polares e tropicais. São eles (SARTORI, 2003, p. 32.34):

Tempo Anticiclonal Polar Típico - Caracteriza-se por altas pressões motivadas pelo estabelecimento do centro do Anticiclone Polar Atlântico (APA), formador da Massa Polar Atlântica, sobre o Rio Grande do Sul.

Tempo Anticiclônico Polar Marítimo - Está relacionado ao domínio da MPA típica (marítima) com o centro barométrico sobre o oceano, mas próximo ao continente, na latitude do Estuário do Rio da Prata e Uruguai (trajetória marítima).

Tempo Anticiclônico Polar Continental - Está associado à Massa Polar Atlântica com trajetória continental, ocorrendo principalmente no inverno, quando ocorre o reforço do abastecimento do ar polar motivado pela Massa Polar Pacífica (MPP) ao extravasar a Cordilheira dos Andes em maiores latitudes, onde a cordilheira possui menores altitudes.

Tempo Anticiclônico Polar Pós-Frontal - Tipo de tempo comum no outonoinverno sul-rio-grandense, ocorrendo logo após a passagem da FPA, que ainda encontra-se sobre o Norte do Rio Grande do Sul e parte de Santa Catarina, com o centro da MPA no oceano, na latitude da Argentina, mas próximo ao continente. Ocorrem nevoeiros classificados pela autora de "nevoeiro polar pósfrontal".

Tempo Anticiclônico Polar em Tropicalização - Ocorre quando há o domínio da MPV, registrando aumento das temperaturas máximas $\left(>25^{\circ} \mathrm{C}\right.$ ) e mínimas $\left(>15^{\circ} \mathrm{C}\right)$, podendo as máximas absolutas atingir valores superiores a $30^{\circ} \mathrm{C}$, bem como registro de grande amplitude térmica.

Tempo Anticiclonal Aquecido - Semelhante ao Tempo Anticiclonal Típico, pois o Anticiclone Polar localiza-se sobre o Estado, mas encontra-se aquecido. 
Mai comum em situações primaveris e vernais, quando ocorre enfraquecimento dos sistemas de origem polar.

Tempo Anticiclônico Tropical Marítimo - Tipo de tempo semelhante ao do Tempo Anticiclônico Polar em Tropicalização, mas relacionado ao domínio da Massa Tropical Atlântica (MTA) sobre o Rio Grande do Sul, favorecendo tempo estável.

Tempo Anticiclônico Tropical Continentalizado - Está relacionado à MTA, que ao se interiorizar pelo território brasileiro, sofre efeitos do aquecimento continental, tornando-se menos úmida e mais quente.

Tempo Depressionário Continental - Resultante da atuação da Massa Tropical Continental (MTC), devido ao aprofundamento da Baixa do Chaco, que eventualmente atinge o Rio Grande do Sul ( $8 \%$ dos dias do ano). Esse tipo de tempo pode ser muito bem caracterizado e individualizado, pois as temperaturas máximas são quase sempre superiores a $35^{\circ} \mathrm{C}$, com pressão atmosférica muito baixa (inferiores até mesmo em comparação com as passagens frontais), ventos do quadrante oeste (W e NW) de intensidade variável. Podem ocorrer Instabilidades Tropicais.

\section{CONCLUSÕES}

Conforme observado na revisão teórica, o clima do Rio Grande do Sul pela sua dinâmica pode ser caracterizado como um clima que possui a participação tanto de sistemas atmosféricos inter e extratropicais, tendo uma maior participação destes últimos em sua gênese. Pela variação dos atributos do clima no território gaúcho, o relevo/geomorfologia consiste no principal fator geográfico de individualização de climas sub-regionais.

Os estudos estáticos de meados dos anos 50 já apresentavam certa variabilidade espacial e temporal do clima do Rio Grande do Sul, com o maior acumulo de registros e evolução dos estudos esta variabilidade foi sendo reavaliada e também passou a se compreender melhor sua gênese.

Nesse sentido, o clima do Rio Grande do Sul possui sazonalidade térmica, e não pluviométrica, de acordo com as classificações das regiões climáticas discutidas por alguns autores.

Por fim, este estudo visou a sistematização de alguns dos principais estudos climatológicos realizados no Estado e procurou sanar um pouco as lacunas existentes. Ainda, esse estudo contribui não só para as indagações do autor, mas também para o rol de pesquisas da Climatologia Geográfica brasileira e sulrio-grandense, servindo, portanto, como fonte teórico-metodológica que possa motivar investigações futuras. 


\section{REFERÊNCIAS}

ARAÚJO, L. C. Memória sobre o clima do Rio Grande do Sul. Rio de Janeiro: Serviço de Informação do Ministério da Agricultura, 1930.

GOVERNO DO ESTADO DO RIO GRANDE DO SUL. Atlas Eólico do Rio Grande do Sul. Porto Alegre, 2006a. 65p.

GOVERNO DO ESTADO DO RIO GRANDE DO SUL. Atlas Socioeconômico e ambiental do Rio Grande do Sul. Porto Alegre, 2006b. 65p.

KÖEPPEN, W. Climatología. México - Buenos Aires: Fondo de Cultura Económica. $2^{\circ}$ edição. 1931.

MACHADO, F. P. Contribuição ao estudo do clima do Rio Grande do Sul. Rio de Janeiro: Serviço Gráfico do IBGE, 1950.

MONTEIRO, C. A. F. O clima da região Sul. In: CATALDO, D. M. (Org.). Geografia do Brasil, Grande Região Sul. Rio de Janeiro: IBGE, 1963. p. 117169.

MOREnO, J. A. Clima do Rio Grande do Sul. Porto Alegre: Secretaria da Agricultura, 1961.

SARTORI, M. G. B. Distribuição das chuvas no Rio Grande do Sul e a variabilidade têmporo-espacial no período 1912-1984. In: SMPÓSIO BRASILEIRO DE GEOGRAFIA FÍSICA E APLICADA. 5., 1993a, São Paulo. Anais... São Paulo: USP, 1993a.

As variações pluviométricas e o regime das chuvas na região central do Rio Grande do Sul. Boletim de Geografia Teorética. n. 23. p. 70-84. 1993b.

- A circulação atmosférica regional e os principais tipos de sucessão do tempo no inverno do Rio Grande do Sul, Brasil. Ciência e Natura, n. 15, p. $69-93,1993$ c.

- A dinâmica do clima do Rio Grande do Sul: indução empírica e conhecimento científico. Revista Terra Livre, São Paulo, v. 1, n. 20, p. 27-49, jan./jul. 2003a.

. Gênese e características do vento norte regional em Santa Maria/RS. In: SIMPÓSIO BRASILEIRO DE GEOGRAFIA FÍSICA E APLICADA, 10., 2003, Rio de Janeiro. Anais... Rio de Janeiro: UERJ, 2003c. 1 CD-ROM.

SARTORI, M. G. B.; ROSSATO, P. S.; SILVEIRA, R. D. Frequência e probabilidade de ocorrência das "Enchentes de São Miguel". In: CONGRESSO BRASILEIRO DE AGROMETEOROLOGIA, 13., 2003, Santa Maria. Anais... Santa Maria: UFSM, 2003b. 1 CD-ROM.

WOLLMANN, C. A. Zoneamento Agroclimático para a Produção de Roseiras (Rosaceae spp.) no Rio grande do Sul. Tese (Doutorado em Geografia Física). Universidade de São Paulo. São Paulo, 2011, 386p. 2v.L 